\title{
An investigation into the forces that drive ice-shelf rift propagation on the Amery Ice Shelf, East Antarctica
}

\author{
Jeremy N. BASSIS, ${ }^{1}$ Helen A. FRICKER, ${ }^{1}$ Richard COLEMAN, ${ }^{2,3,4}$ \\ Jean-Bernard MINSTER ${ }^{1}$ \\ ${ }^{1}$ Institute for Geophysics and Planetary Physics, Scripps Institution of Oceanography, \\ University of California-San Diego, La Jolla, California 92093-0225, USA \\ E-mail: jbassis@ucsd.edu \\ ${ }^{2}$ Center for Marine Science, University of Tasmania, Hobart, Tasmania 7000, Australia \\ ${ }^{3}$ CSIRO Marine and Atmospheric Research, Box 1538, Hobart, Tasmania 7001, Australia \\ ${ }^{4}$ Antarctic Climate and Ecosystems CRC, Box 252-80, Hobart, Tasmania 7001, Australia
}

\begin{abstract}
For three field seasons $(2002 / 03,2004 / 05,2005 / 06)$ we have deployed a network of GPS receivers and seismometers around the tip of a propagating rift on the Amery Ice Shelf, East Antarctica. During these campaigns we detected seven bursts of episodic rift propagation. To determine whether these rift propagation events were triggered by short-term environmental forcings, we analyzed simultaneous ancillary data such as wind speeds, tidal amplitudes and sea-ice fraction (a proxy variable for ocean swell). We find that none of these environmental forcings, separately or together, correlated with rift propagation. This apparent insensitivity of ice-shelf rift propagation to short-term environmental forcings leads us to suggest that the rifting process is primarily driven by the internal glaciological stress. Our hypothesis is supported by order-of-magnitude calculations that the glaciological stress is the dominant term in the force balance. However, our calculations also indicate that as the ice shelf thins or the rift system matures and iceberg detachment becomes imminent, shortterm stresses due to winds and ocean swell may become more important.
\end{abstract}

\section{INTRODUCTION}

The fourth Intergovernmental Panel on Climate Change (IPCC) assessment report concluded that the Antarctic ice sheet is losing mass, but that current estimates of mass loss are highly uncertain (Lemke and others, 2007). The report emphasized deficiencies in our understanding of relatively rapid (i.e. decades to century scale) changes occurring at ice-sheet margins and did not include these dynamic icesheet changes in its sea-level projections. This has exposed an urgent need to improve our understanding of processes acting at the margins of the ice sheets.

In Antarctica, the primary mechanism for mass loss is iceberg calving ( $75 \%$ ); the other major mass-loss mechanism is basal melting ( 25\%) (Jacobs and others, 1992). Basal melt rates have been estimated for most of the major ice shelves (e.g. Joughin and Padman, 2003), but calving rates are more uncertain. The timescale between major iceberg calving events on ice shelves is long (typically several decades), and such events form part of the natural cycle of advance (by ice flow) and retreat (by calving) of the ice front. Although major calving events occur sporadically, when they do occur they remove large amounts of mass in a near-instantaneous fashion. Thus a small increase in the frequency of large calving events could lead to substantial negative mass balance. Furthermore, the acceleration of tributary glaciers in the wake of the collapse of the Larsen B ice shelf in the Antarctic Peninsula (Rignot and others, 2004; Scambos and others, 2004) has demonstrated that ice shelves are not merely passive indicators of climate change, but are dynamically coupled to flow of inland ice and capable of modulating ice flow far upstream of the grounding line. Thus, even though the retreat or loss of ice shelves does not significantly affect sea-level rise, their demise affects the discharge of grounded ice, which contributes directly to sealevel rise.

It is known that the calving process involves the initiation and propagation of large-scale 'rifts', i.e. fractures that penetrate the entire ice thickness, and that ice-shelf rifts can propagate horizontally for decades before multiple rifts isolate an iceberg. However, very little is known about the forces and mechanisms controlling rift propagation, a limitation primarily due to the paucity of available observations. The rift propagation process is clearly linked to flow dynamics over a wide range of environmental conditions, flow regimes and spatial domains. However, the details of this connection are not yet known, and there is debate about such basic questions as what forces drive rift propagation (Larour and others, 2004; Bassis and others, 2005; Joughin and MacAyeal, 2005; MacAyeal and others, 2007). Without this knowledge, it is impossible to formulate a mathematical model of iceberg calving, or to realistically incorporate the process into larger-scale numerical ice-sheet/ice-shelf/ ocean models.

Since ice shelves are in contact with both the atmosphere and the ocean, there are a number of environmental forces that may drive rift propagation in addition to the large-scale glaciological stress caused by the gravitational spreading of the ice. For instance, it has been suggested that flexuralgravity waves may trigger rift propagation (Holdsworth and Glynn, 1978; Goodman and others, 1980), a theory that was resurrected when MacAyeal and others (2007) noticed that the break-up of iceberg B15A correlated with the arrival of a large pulse of ocean swell. Vertical tidal oscillations may bend the ice, inducing stresses that, if large enough, may trigger rift propagation. At the base of the ice shelf, tidally 


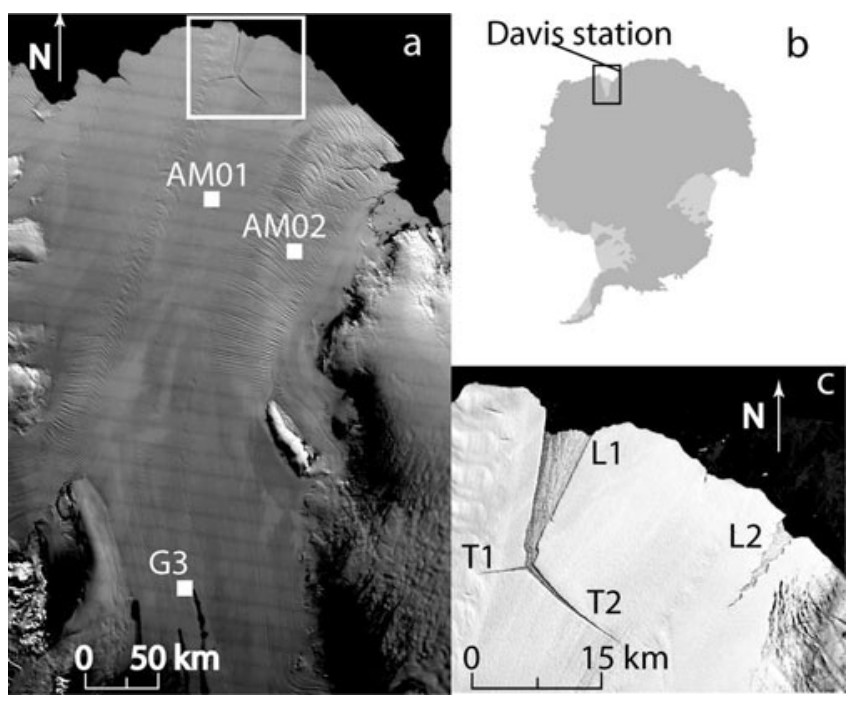

Fig. 1. (a) MODIS (moderate-resolution imaging spectroradiometer) image acquired on 18 January 2006 showing the Amery Ice Shelf and the 'Loose Tooth' rift system. White squares show the position of the three ice-shelf-based AWS sites, AM01, AM02 and G3. (b) Line map showing the location of the Amery Ice Shelf in East Antarctica. The tide gauge was located at Davis. (c) Landsat image acquired on 18 December 2002 showing a close-up of the Loose Tooth rift system. The L1-T1-T2 triple junction was first observed in 1995. Since then L1 has widened but has not increased in length.

driven sub-ice-shelf currents exert a drag force which could induce propagation. At the ice-shelf surface, the cold dense air from katabatic winds (blowing down onto the ice shelf and across the rift) combined with large Antarctic storm systems can produce large wind fields that also result in substantial frictional drag force. When either of these two drag forces (basal or surface) is integrated over a large enough area, it may result in a substantial stress applied to the ice shelf. In addition to the above variables that directly exert a stress on the ice shelf, there are variables that indirectly modulate the stress. The presence of sea ice, for example, will dampen the amplitude of ocean swell (Wadhams, 2000), and above-freezing atmospheric temperatures may promote hydro-fracturing of the ice via the production of surface melt (Scambos and others, 2003; Alley and others, 2005).

Thus the crucial first step in improving our knowledge of iceberg calving is identifying which force(s) are responsible for driving rift propagation. To achieve this, we deployed a densely spaced network of seismometers and global positioning system (GPS) receivers around the tip of a propagating rift on the Amery Ice Shelf, East Antarctica, for three austral summer field seasons (Bassis and others, 2005, 2007). Our observing network was supplemented by automatic weather stations (AWS) and tide gauges operated by the Australian Antarctic Division (AAD). This instrumentation provided us with ancillary observations of relevant environmental variables, against which we could compare our network data. We augment the field component of this study with a time series of satellite-derived rift lengths published by Fricker and others (2005) and extended through 2006. These data provide additional information about the rift propagation rate on longer timescales (monthly and longer).

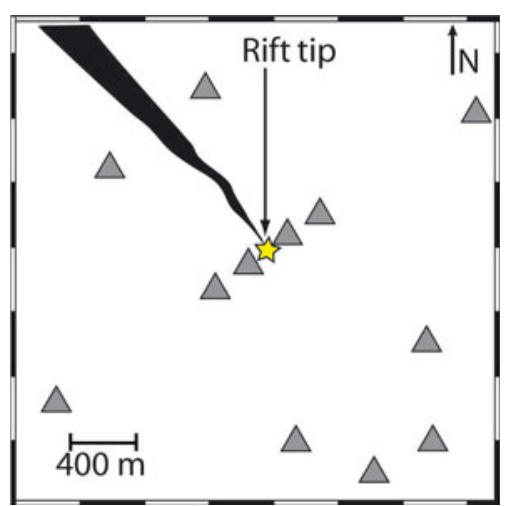

Fig. 2. Diagram showing the relative positions of observing stations (gray triangles) relative to the tip of rift T2 (gold star) for seasons 2 and 3. Different stations and a different geometry were used for season 1. However, the network was centered on the rift tip each season.

\section{AMERY ICE SHELF RIFT-MONITORING PROGRAM (2003-07)}

\subsection{Location of study and instrumentation}

Our field study was designed to monitor a system of rifts that have formed near the front of the Amery Ice Shelf (Fig. 1). The rift system consists of two longitudinal-to-flow rifts $\sim 30 \mathrm{~km}$ apart that initiated about 20 years ago (L1 and L2) and two transverse-to-flow rifts (T1 to the west and $\mathrm{T} 2$ to the east) that initiated at the tip of $\mathrm{L} 1$, forming a triple junction first observed in 1996 (Fricker and others, 2002). This rift system forms the outline of an intermediate-sized iceberg ( $30 \mathrm{~km}$ by $30 \mathrm{~km}$ ), termed the 'Loose Tooth', that is expected to detach within the next decade. Rift T2 currently propagates at approximately $4 \mathrm{~m} \mathrm{~d}^{-1}$, and when T2 connects with L2, the Loose Tooth iceberg will likely detach.

Our field site was located near the tip of T2, where we deployed a network of seismometers and GPS receivers during each austral summer season. The geometry of one such deployment is shown in Figure 2. Although our instrumentation and network geometry varied each season, the center of the network was translated to correspond to the approximate location of the rift tip observed in the field. In 2002/03 we deployed eight stations which acquired data for 42 days: six with a single-component $\mathrm{L}-4 \mathrm{C}$ seismometer recording at $10 \mathrm{~Hz}(0.1 \mathrm{~s})$ and a dual-frequency GPS receiver recording at $0.033 \mathrm{~Hz}(30 \mathrm{~s})$, and two seismometer-only stations. In 2004/05 and 2005/06 we increased the number of stations to twelve, each with a three-component L-28 seismometer, digitized with a Quanterra Q330 data logger and a dual-frequency GPS receiver recording at $0.5 \mathrm{~Hz}(2 \mathrm{~s})$ for 52 and 81 days respectively. Hereafter we refer to the three field seasons as follows: 2002/03 is 'season 1'; 2004/ 05 is 'season 2'; 2005/06 is 'season 3'. To facilitate comparison of timing between field seasons, we reference days of our survey relative to day of year (DOY) 332. In addition to our observing stations, the AAD operated AWS on the Amery Ice Shelf, one located $\sim 100 \mathrm{~km}$ upstream from our network (shown in Fig. 1).

\subsection{Previous results}

Fieldwork

We have previously shown that over the three field seasons of our measurements we detected seven bursts of rift propagation: three during season 1 , three during season 2 

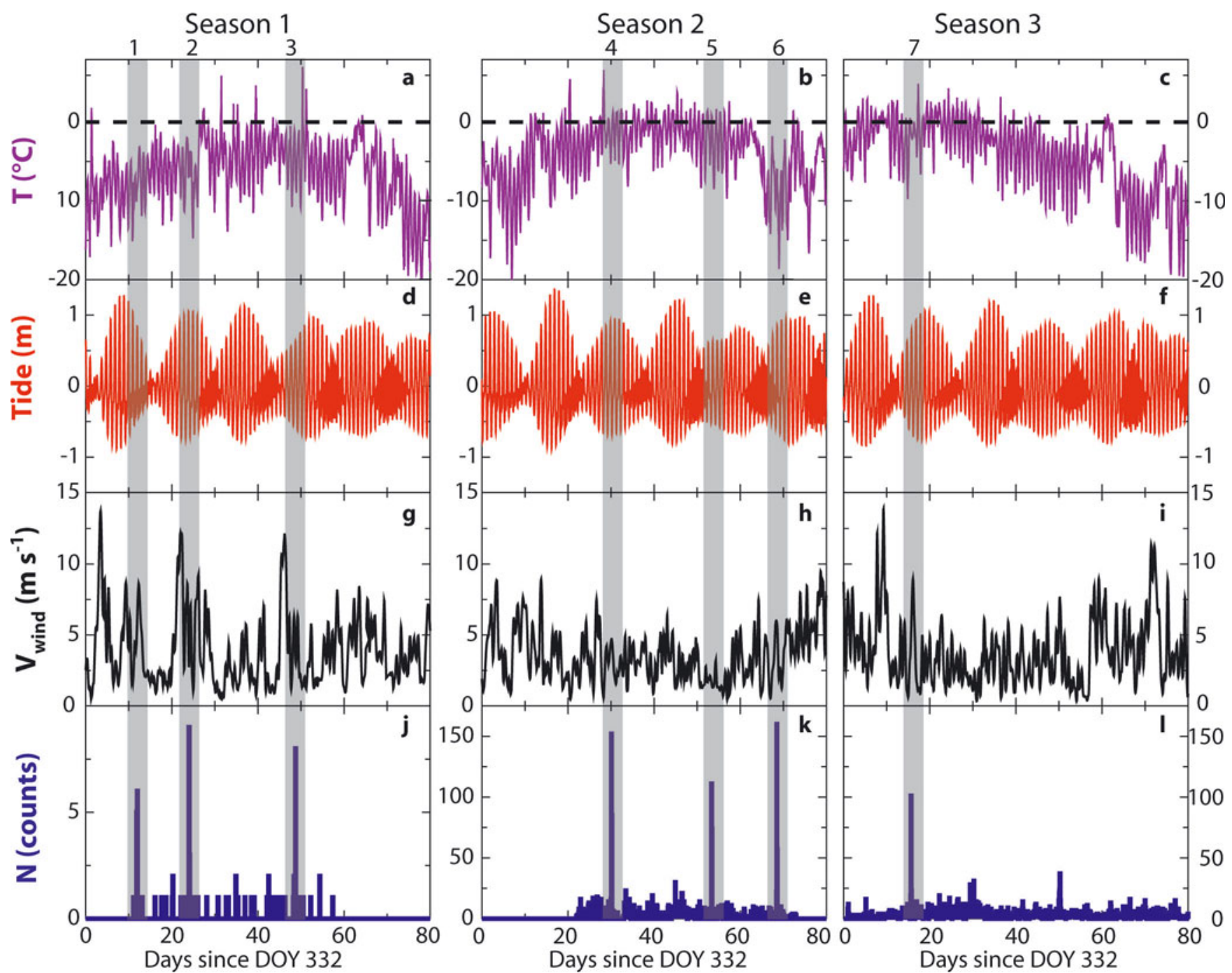

Fig. 3. Comparison of the amplitudes of winds, tides and atmospheric temperature with the timing of seismic swarms for all three field seasons: season $1(\mathrm{a}, \mathrm{d}, \mathrm{g}$, j); season 2 (b, e, h, k); and season $3(\mathrm{c}, \mathrm{f}, \mathrm{i}, \mathrm{l})$. (a-c) Atmospheric temperature determined from AWS AM01 and AM02 (see Fig. 1 for locations) for each field season. (d-f) Tidal amplitudes computed from the CATS02.01 tidal model (Padman and others, 2002) for each field season. (g-i) Wind speeds measured at AWS AM01 and AM02 for each field season. (j-I) Histogram of rift-related seismicity. $N$ is the number of events per bin (bin size 3 hours). The seven propagation events that we observed are labeled and highlighted with gray shaded boxes. Note the difference in scales between season 1 and seasons 2 and 3. An increase in the number of seismometers and their sampling rate increased the sensitivity to icequakes by more than an order of magnitude.

and one during season 3 (Bassis and others, 2005, 2007). Each burst, deduced from swarms of rift-related 'icequakes' (detected by our seismic network) coincident with rapid riftwidening (detected with our GPS receiver network), lasted approximately 1-4 hours (Fig. 3j-I). Swarms consisted of approximately 10-100 times the background number of icequakes. In between swarms, the background rate of icequake production was relatively constant. Our hypothesis that the bursts of propagation were caused by episodic rift propagation was reinforced by the pattern of event locations, which showed that the icequakes were tightly clustered along the rift axis near the rift tip.

\section{Satellite observations}

On longer timescales, analysis of rift propagation rates using multi-year satellite imagery has provided evidence of seasonal variability in rift propagation rates (Fricker and others, 2005). In that paper, satellite images from the Multiangle Imaging Spectroradiometer (MISR) acquired from 1999 to 2004 were used to show that rifts lengthen more in the austral summer period (September-April) than in the winter period (April-September). Images are not available during winter since the lack of solar illumination prevents image acquisition. We use an extended time series (through to 2006) in this paper (Fig. 4, lower panels). Figure 4 shows the satellite-derived change in rift length $\Delta L$ over five summer periods from 2001/02 through 2005/06. For each summer, we define the change in rift length $(\Delta L)$ as the amount the rift lengthened since the last measurement of the previous summer, i.e. the first point shows how much the rift lengthened over the winter. It is clear that for most years the majority of rift propagating occurs during the austral summer (Fricker and others, 2005).

\section{FORCES THAT MAY DRIVE RIFT PROPAGATION}

\subsection{Force balance}

We seek to determine whether short-term variations in the state of stress trigger the observed rift propagation events. (Short-term, in the context of this study, is defined as 


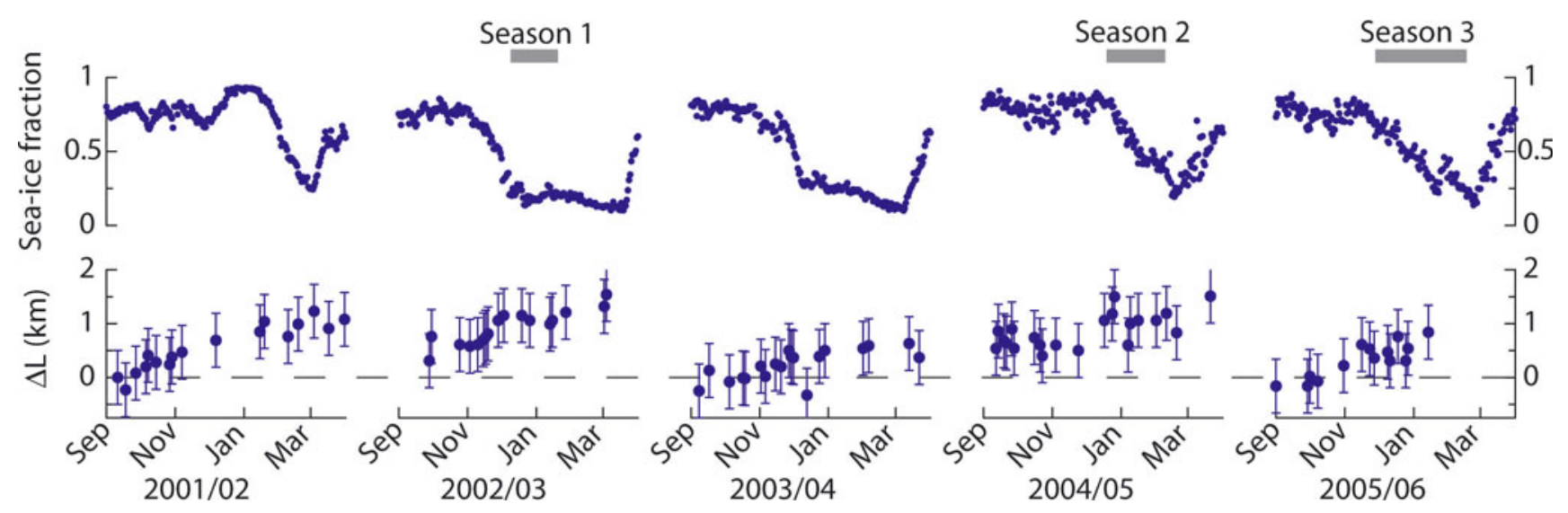

Fig. 4. Upper panel: Average sea-ice fraction over a $100 \mathrm{~km}$ region in front of the Amery Ice Shelf. Sea-ice fraction was determined from the NCEP MMAB sea-ice model. Lower panel: Change in rift length $(\Delta L)$ over each austral summer field season. $\Delta L$ for each season is defined as the difference between the rift length at time $t_{\mathrm{i}}$ and the length of the rift at the end of the previous season. Gray bars show the timing and duration of each field season.

monthly or shorter.) Since the ice shelf is influenced by both internal and external environmental variables, we perform a force balance on a unit area of the ice shelf (see, e.g., Wadhams, 2000):

$$
\rho_{\mathrm{i}} \mathrm{a} H_{\mathrm{i}}=\tau_{\mathrm{a}}+\tau_{\mathrm{w}}+\tau_{\text {tide }}+\tau_{\text {swell }}+\tau_{\mathrm{i}}+\tau_{\mathrm{t}}+\tau_{\mathrm{c},}
$$

where $H_{\mathrm{i}}, \rho_{\mathrm{i}}, \mathrm{a}$ are the ice thickness, density and acceleration, $\tau_{\mathrm{a}}$ is the drag on the ice surface caused by the winds, $\tau_{\mathrm{w}}$ is the drag stress due to ocean currents on the bottom of the ice shelf, $\tau_{\text {tide }}$ and $\tau_{\text {swell }}$ are the bending stresses within the ice induced by tides and ocean swell, $\tau_{\mathrm{i}}$ is the glaciological stress of the ice, $\tau_{\mathrm{c}}$ is the Coriolis force and $\tau_{\mathrm{t}}$ is the stress induced by slopes of the sea surface. Once the iceberg completely detaches and drifts freely, inertial terms may become significant. However, our interest is in the period prior to detachment when inertial terms can be neglected because of the low ice velocity, so we set the lefthand side of Equation (1) to zero. In addition to these variables that directly transmit a force to the ice shelf, sea-ice concentration and atmospheric temperature may indirectly

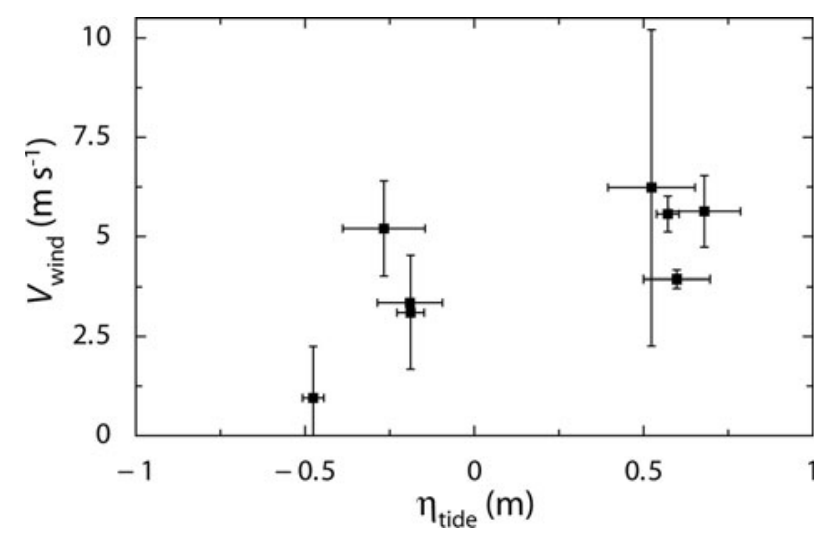

Fig. 5. Wind speed vs tidal amplitude for all seven propagation events. Both wind speed and tidal amplitude were obtained from the 3 hour average over the duration of the swarm. Uncertainties represent the standard deviation of values in a 3 hour window around the onset of the swarm. The large scatter in the data indicates that propagation events do not occur at times of high tidal amplitude, severe winds or even a combination of high tidal amplitude and severe winds. affect the force balance by damping the amplitude of ocean swell and promoting meltwater-assisted hydro-fracturing, respectively.

\subsection{Measurements}

To evaluate the sensitivity of rift propagation to variations in environmental stresses, we considered the relationship between rift propagation events and each of the environmental parameters on the righthand side in Equation (1):

Wind speed. We compared the timing of the rift propagation events with wind speeds measured by nearby ice-shelf-based AWS (AM01 and AM02) operated by the AAD (personal communication from M. Craven and I. Allison, 2007). We also examined the effect of longer-term mean wind fields by comparing variations in rift propagation rates to the mean wind speed, also determined using data from the AWS.

Tidal amplitude. We compared the timing of the rift propagation events with the phase and amplitude of the tide, computed using the CATS02.01 tidal model (Padman and others, 2002) and measured directly with our GPS. Because the currents are phase-locked to the amplitude of the tides, by determining if there is a relationship between the phase of the tide and propagation events we can also determine if tidally induced ocean currents drive rift propagation.

Ocean swell. Since satellite- and model-derived wave heights lack the combination of spatial and temporal resolution required to resolve the amplitude and period of ocean swell for each propagation event, we do not have direct information about the amplitude and period of the wave field in front of the ice shelf. Instead, we used a proxy variable for ocean swell, sea-ice fraction, determined using the US National Centers for Environmental Prediction/Marine Modeling and Analysis Branch (NCEP MMAB) sea-ice model (http://polar.ncep. noaa.gov/seaice/). The presence of sea-ice will attenuate the amplitude of ocean swell, so a higher sea-ice fraction implies lower ocean swell amplitude. We compared (1) the timing of the rift propagation events and (2) rift propagation rates with sea-ice fraction. 

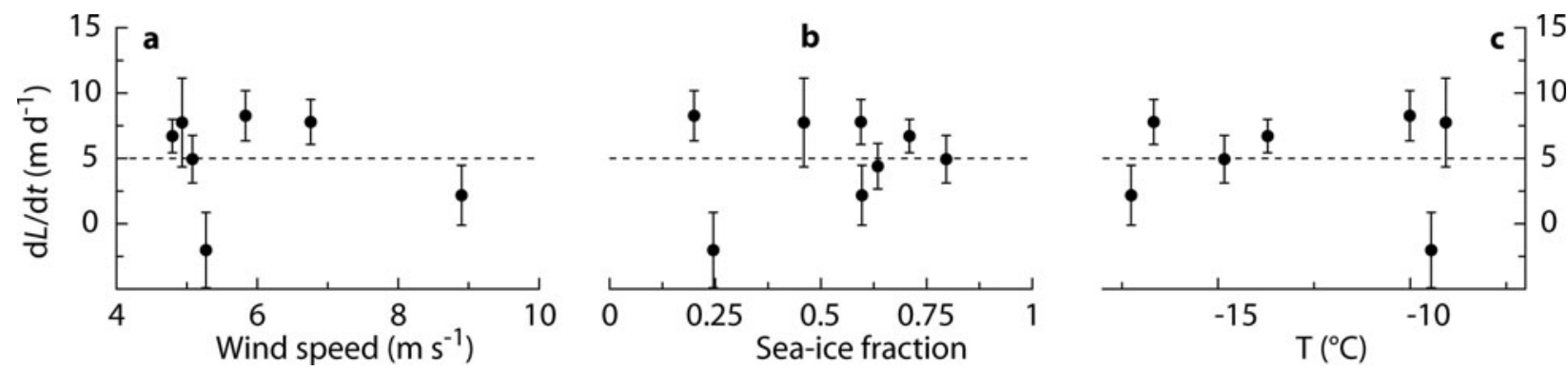

Fig. 6. Rift propagation rates $(\mathrm{d} L / \mathrm{d} t)$ determined for the September-January and January-April periods against: (a) average wind speed; (b) mean sea-ice fraction; (c) mean temperature. The dashed line indicates the mean of rift propagation rates. There is no correlation between rift propagation rates and any of the variables.

We neglect both the Coriolis force $\left(\tau_{\mathrm{c}}\right)$ and the sea surface tilt $\left(\tau_{\mathrm{t}}\right)$ in our analysis because we expect both of these terms to be small in comparison to the other terms in the force balance. We examine this assumption in more detail in section 5.2. Since our observing stations during season 2 were deployed several weeks prior to the 26 December 2004 Sumatra earthquake and the tsunami it generated, we were able to investigate if the tsunami triggered a rift propagation event. We compared the timing of the rift propagation events with the time of arrival of (1) surface waves from the earthquake (detected with our seismometers) or (2) the arrival of the tsunami (detected with our GPS and tide gauges operating at Davis station).

The final environmental variable we consider is atmospheric temperature. To assess whether variations in temperature modulate rift propagation rates, we compared (1) the timing of rift propagation events with AWS-derived atmospheric temperatures and (2) variations in rift propagation rates with mean temperature. On the Amery Ice Shelf, longer-term variations in temperature and meltwater production may be more significant factors than the short-term variations that are the focus of this study.

\section{RESULTS}

\subsection{Wind speed and tidal amplitude}

Figure 3 shows the time series of seismicity, wind speed and tidal amplitude determined using the CATS02.01 tidal model for seasons 1, 2 and 3, with the times of the seven rift propagation events overlain (shaded rectangles). Events 2 and 3 in season 1 were preceded by periods of severe winds. However, this relationship does not hold for any of the other events. For instance, all of the events during season 2 were preceded by relatively gentle winds. Tidal amplitude ranged from approximately +1.2 to $-1.2 \mathrm{~m}$ over the three seasons (shown with a dashed line). There appears to be no relationship between tidal amplitude/phase and rift activity: none of the events occurred near tidal maxima. Only events 2 and 4 occurred close to high tide, and event 5 actually occurred near the lowest tidal amplitude. Because rift propagation events occur at a variety of tidal states and wind speeds, we find no evidence that either of these variables is directly responsible for triggering rift propagation events.

We considered the possibility that a combination of winds and tides triggers propagation, and plotted wind speed against tidal amplitude for each event (see Fig. 5). To determine the amplitude of tides and winds during each swarm, we used the average value over a 3 hour period surrounding the onset of each event ( 3 hours is the approximate uncertainty in the timing of the onset of each event). We then estimated uncertainties in the tidal amplitude and wind speed using the standard deviation over the 3 hour period. We would expect that: (1) if high or low tides triggered rift propagation, all the points would cluster along the left or right portions of the graph; (2) if winds were solely responsible for triggering rift propagation, the points would tend to cluster along the top portion of the graph; and (3) if high tidal amplitudes and severe winds are both necessary to trigger propagation events, points would cluster in the upper righthand quadrant of the plot. We see that none of these scenarios are supported by the data. Instead, events cluster into a relatively small tidal range and occur at a variety of wind speeds scattered throughout the figure domain. From this we conclude that high winds or tides do not directly trigger rift propagation.

Another possibility is that the multi-month (or longer) averaged wind speeds are more important than short-term variations. This would imply that rift propagation should be faster during the winter, when wind speeds are highest. However, Fricker and others (2005) analyzed T1 and T2 rift lengths using satellite imagery and found that the opposite is true (see also lower panels in Fig. 4). To evaluate the influence of winds on monthly timescales, we computed the rift propagation rate and average wind speed for each year during the periods September-January and January-April (Fig. 6a). We see no correlation between variations in rift propagation rate and average wind speed. We conclude that winds alone are unlikely to be the primary driver of rift propagation.

\subsection{Ocean swell}

To estimate the sea-ice fraction, our proxy variable for ocean swell, we averaged the NCEP-derived sea-ice fraction over a $100 \mathrm{~km}$ radius in front of the Amery Ice Shelf, approximately twice the embayment width. Our results are not sensitive to the choice of averaging interval. Using smaller averaging merely results in increased scatter. Figure 4 shows the seaice fraction (upper panels) over each austral summer, defined here to be September-April. Gray bars show the timing and duration of each field campaign. Although there is some interannual variability in sea-ice fraction, the broad trend is that sea-ice fraction is high between September and December, begins to decrease to its minimum value in late December or early January and then rises rapidly around March or April. Four of the seven rift propagation events $(1,2,4$ and 7$)$ occurred prior to 1 January, and the remaining 


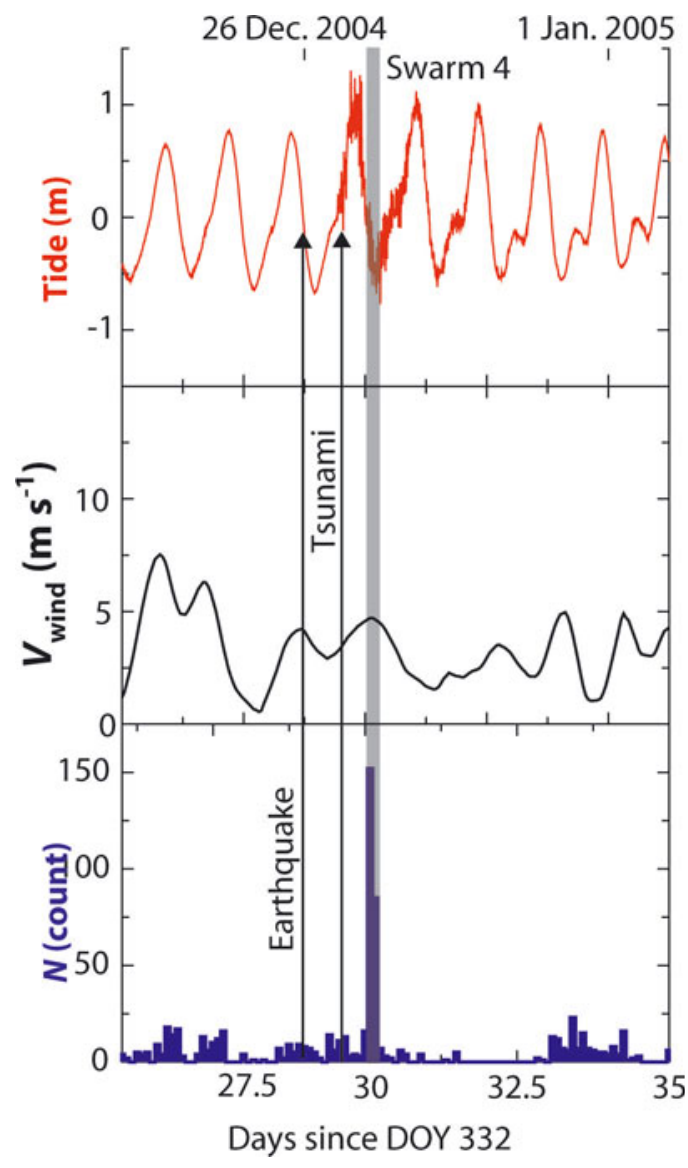

Fig. 7. Upper panel: Tide gauge from Davis station showing the arrival of the tsunami. Middle panel: Wind speeds measured at AWS on the Amery Ice Shelf. Lower panel: Histogram showing the number of events in 3 hour bins. The arrival of the Sumatra earthquake and its accompanying tsunami are indicated with arrows.

three occurred after 1 January. This is contrary to what we would expect if sea ice were buffering the ice shelf from ocean-swell-triggered rift propagation. If we normalize the number of events detected during each period (i.e. before 1 January and after 1 January) by the total number of observations days before and after January, we find that the rate of rift propagation events remains slightly higher in the pre-January period (0.06 vs 0.04 events per day) when seaice fraction is highest. This suggests that changes in sea-ice fraction, and by association in ocean swell, are not a dominant factor in rift propagation.

We also compared sea-ice fraction with rift propagation rates on longer timescales, estimated from MISR satellite imagery. Figure 4 shows that at the start of each summer, $\Delta L$ is close to zero, indicating that the rift lengthened little over the austral winter, a period of high sea-ice fraction. For most seasons, rift propagation begins to increase between September and October, when sea-ice fraction is close to its maximum. This is seen more clearly in Figure $6 \mathrm{~b}$ which shows the rift propagation rate (determined using a leastsquares fit) against average sea-ice fraction determined for: (1) the period September-January when sea ice is close to its maximum and (2) the period January-March when sea ice is close to its minimum. Rift propagation shows no correlation with sea-ice fraction (correlation coefficient is 0.28 ) and we therefore conclude that rift propagation rates are not controlled by the presence (or lack) of sea-ice.

\subsection{Sumatra earthquake and tsunami}

The tide gauge record from Davis station (see Fig. 1 for location) along with the wind speed and the seismicity are shown in Figure 7 . The tide gauge record shows that the tsunami arrived about 13 hours after the earthquake. This is in excellent agreement with the predicted arrival time of the tsunami assuming a shallow water wave velocity of $170 \mathrm{~m} \mathrm{~s}^{-1}$ corresponding to a mean ocean depth of $3 \mathrm{~km}$ (e.g. Gill, 1982). We see no increase in the frequency of icequakes following the arrival of the earthquake surface waves (nor the seismic waves of any of its aftershocks), indicating, not surprisingly, that vibrations from the earthquake did not trigger rift propagation. Closer examination of Figure 7 shows that superposition of high tidal amplitudes and the tsunami also did not trigger rift propagation. Instead, the burst of propagation occurred during a period of relatively low tidal amplitude. From this we conclude that, at least on a near-instantaneous timescale, the arrival of the tsunami, even in combination with tidal forcing, did not trigger rift propagation. However, we see that swarm 4 occurred about 1 day after the arrival of the tsunami. Even though the tsunami did not directly trigger a propagation event, prolonged vibrations associated with the tsunami may have contributed to 'fatigue' within the ice and have ultimately led to the burst of propagation 1 day later. While the connection between the rift propagation event and the tsunami 1 day later is intriguing, it could be a coincidence. To test for this possibility, we adopted the simplest statistical model for a point process wherein each propagation event is governed by a Poisson process with a recurrence interval of 10-24 days. (The probability of a large earthquake has also been modeled as a Poisson process.) With this assumption, the probability that we observe one burst of propagation within a 2 day time window is $10-20 \%$. Thus we cannot rule out the possibility that the timing between the burst of propagation and the arrival of the tsunami is random at the 95\% confidence level. Although this statistical analysis relies on many assumptions, it demonstrates the difficulty in determining a causal relationship between two potentially stochastic variables with limited data.

\subsection{Atmospheric temperature}

The effect of temperature is more difficult to ascertain. Figure $3 \mathrm{a}-\mathrm{c}$ show the atmospheric temperature recorded at AWS AM01 and AM02 for each field season. The Loose Tooth is about $100 \mathrm{~km}$ further north than these stations, so temperatures along the rift may be slightly higher. However, the pattern of temperature change will remain the same. Figure 3 shows that atmospheric temperatures are typically below freezing over most of the austral summer, with mean temperatures over each field campaign ranging between $-6^{\circ} \mathrm{C}$ and $-7^{\circ} \mathrm{C}$, with mean January temperatures of $-3.5^{\circ} \mathrm{C}$. Superimposed on top of the longer-term trend are diurnal temperature variations that reach as high as $5^{\circ} \mathrm{C}$. It is possible that some of the events are related to abovefreezing temperatures. For instance, events 4 and 6 occurred after brief positive temperature excursions. Events 5 and 6 were also preceded by several days with peak temperatures above freezing. Events 1, 2, 3 and 7, however, occurred after periods when the temperatures were consistently below zero. Moreover, no meltwater ponding has been observed near the front of the Amery Ice Shelf to date. 
The ambiguous relationship of rift propagation with temperature is probably because the Loose Tooth rift system is still in a cold regime, not yet perturbed by surface melt. Figure $6 \mathrm{c}$ shows the mean temperature plotted against rift propagation rate for the September-January and JanuaryApril periods each year. There is no obvious correlation between rift propagation rate and temperatures, which is substantially below zero for all data points. This suggests that surface melt is not yet a significant factor driving rift propagation in the Loose Tooth region.

\section{DISCUSSION}

\subsection{Relation between rift propagation and environmental forces}

We have found no evidence linking rift propagation to environmental forcing. It is, however, possible that environmental conditions outside the parameter regime that we measured can trigger rift propagation (e.g. a tsunami with much larger amplitude or large-amplitude ocean swell generated by a giant storm system). What our analysis does show is that short-term extrema are not necessary conditions to trigger rift propagation. It is possible that more complicated models for the accumulation and release of stress for each variable need to be considered. For example, we could consider a model in which the glaciological stress accumulates between propagation events; once the accumulated stress approaches a threshold value, smaller-scale variations in the stress due to winds, tides or swell may push the stress over the threshold, causing a propagation event. Alternatively, cyclical forcing by tides, winds or ocean swell could result in cumulative fatigue. A full examination of this possibility is beyond the scope of this study and the data we have collected to date. Instead, we conclude that if shortterm variations in tides or winds or sea-ice fraction (ocean swell) do influence rift propagation, they do so indirectly.

The apparent insensitivity of rift propagation to short-term variations in tides and winds is surprising, given that iceberg drift is known to be controlled by wind stress, water stress and Coriolis forces (Wadhams, 2000) and it is known that strong offshore winds preceded the final disintegration of the Larsen B ice shelf (Rott and others, 2002). Why then are these forces significant for iceberg drift, but insignificant in driving rift propagation? One possibility is that at an early stage of development, rift propagation is dominated by the glaciological stress of the ice shelf. At a later stage, as the rift system matures and the proto-berg approaches detachment, it becomes less and less coupled to the main ice shelf, and environmental variables become increasingly important. We examine this hypothesis next by returning to the force balance previously introduced (section 3 ) and estimating the magnitude of each of the terms.

\subsection{Re-examination of force-balance terms}

\section{Glaciological stress $\left(\tau_{\mathrm{i}}\right)$}

The glaciological stress within the ice shelf is primarily related to the density difference between ice $\left(\rho_{\mathrm{i}}\right)$ and water $(\rho)$ (Weertman, 1957). This stress may be partly balanced by shear along the walls or resistance from pinning points or ice rises. However, the Loose Tooth rift system is close to the center of the ice shelf and there are no ice rises in the vicinity. We therefore approximate the ice shelf as freely spreading. Following Weertman (1957), the stress within the ice shelf is then related to the ice thickness and densities of ice and water:

$$
\tau_{\mathrm{i}}=\rho_{\mathrm{i}} g H_{\mathrm{i}}\left(1-\frac{\rho_{\mathrm{i}}}{\rho_{\mathrm{w}}}\right),
$$

where $\rho_{\mathrm{i}}$ is the density of ice and $\rho_{\mathrm{w}}$ is the density of sea water and, because the surface slope near the front is small, we have neglected the effect of gradients in the ice thickness. For an ice thickness ranging from 200 to $400 \mathrm{~m}$, we estimate a glaciological stress that ranges from 180 to $350 \mathrm{kPa}$. Because the large-scale glaciological stress is primarily controlled by ice thickness and embayment geometry, we expect it will not change significantly over the timescale of our field campaigns (e.g. the change in ice thickness due to spreading and/or melting/refreezing is small over the $\sim 80$ days of our surveys). However, the glaciological stress may be modulated somewhat by the accumulation of melange, a mixture of snow and ice within the rift.

\section{Coriolis force $\left(\tau_{\mathrm{c}}\right)$}

The Coriolis force arises due to the rotation of the Earth. Therefore, measurements made relative to the surface of the Earth are not in an inertial reference frame. Although the Coriolis force is important in determining trajectories for sea-ice and iceberg drift (Wadhams, 2000), typical ice-shelf velocities are small $\left(\sim 10^{-5} \mathrm{~m} \mathrm{~s}^{-1}\right)$ and therefore the Coriolis force is also small. Quantitatively, the Coriolis force is given by (Wadhams, 2000)

$$
\tau_{\mathrm{c}}=\rho_{\mathrm{i}} H_{\mathrm{i}} \cup f,
$$

where $U$ is the velocity of ice and $f$ is the Coriolis parameter,

$$
f=2 \Omega \sin \phi .
$$

In Equation (4), $\Omega$ is the rate of angular rotation of the Earth and $\phi$ is the latitude. Assuming an ice-flow velocity of $4 \mathrm{~m} \mathrm{~d}^{-1}$ $\left(\sim 5 \times 10^{-5} \mathrm{~m} \mathrm{~s}^{-1}\right), H_{\mathrm{i}}$ of $400 \mathrm{~m}$, ice density of $920 \mathrm{~kg} \mathrm{~m}^{-3}$ and $f$ on the order of $10^{-5} \mathrm{~s}^{-1}$ results in $\tau_{\mathrm{c}}$ on the order of $10^{-3} \mathrm{kPa}$. This is small compared to the glaciological stress, suggesting that until the iceberg starts to drift, the Coriolis force is a negligible term in the force balance supporting our initial assumption.

\section{Sea surface tilt $\left(\tau_{\mathrm{t}}\right)$}

Sea surface tilt arises because the sea surface does not exactly correspond to an equipotential surface. The difference between the two surfaces induces a pressure gradient in the water column. For sea ice, it is found that the sea surface tilt is important over long periods of time (weeks to months) but is insignificant over shorter periods of time (days) (Wadhams, 2000). The stress induced by the sea surface tilt is given by the expression

$$
\tau_{\mathrm{t}}=-\rho_{\mathrm{i}} g H_{\mathrm{i}} \nabla \eta_{\text {sea, }}
$$

where $\nabla \eta_{\text {sea }}$ is the sea surface slope. For typical sea surface slopes of $10^{-3}-10^{-4}$ (Wadhams, 2000), this results in a sea surface tilt stress of $\tau_{\mathrm{t}}=0.1-1 \mathrm{kPa}$. Again, this is small compared to the glaciological stress of ice and not likely to be important in driving rift propagation.

\section{Wind stress $\left(\tau_{\mathrm{a}}\right)$}

Observations show that the wind exerts a frictional force on the surface of the ice that is proportional to the square of the wind speed (Wadhams, 2000)

$$
\tau_{\mathrm{a}}=C_{\mathrm{a}} \rho_{\mathrm{a}} U_{\mathrm{a}}^{2},
$$


where $\rho_{\mathrm{a}}$ is the density of air $\left(\sim 1 \mathrm{~kg} \mathrm{~m}^{-3}\right), U_{\mathrm{a}}$ is the wind speed $\left(\sim 50 \mathrm{~m} \mathrm{~s}^{-1}\right)$ and $C_{\mathrm{a}}$ is the drag factor. The drag coefficient is an empirical constant that depends on the surface roughness of the ice. It is occasionally separated into a 'form' drag that depends on larger-scale topography and roughness of the ice, and a 'skin' drag that is approximately constant. For most applications, the drag (combination of form and skin) can range in value from $10^{-2}$ to $10^{-3}$, where the upper values of the order of $10^{-2}$ would involve considerable large-scale roughness (Wadhams, 2000). Typical magnitudes of wind speeds deduced from AWS on the Amery Ice Shelf are in the range of several to tens of meters per second, resulting in a typical stress of $\tau_{\mathrm{a}} \sim 1-20 \times$ $10^{-3} \mathrm{kPa}$. This stress is relatively small, but if integrated over a large surface area it could become significant. Wind stress far upstream of the rift is unlikely to have any effect on rift propagation. Therefore, a reasonable estimate for the maximum force that the wind can apply to the rift system is to integrate the wind stress over the area of the proto-berg $\left(A_{\text {berg }}\right)$ enclosed by the rift system:

$$
F_{\mathrm{a}}=C_{\mathrm{a}} \rho_{\mathrm{a}} U_{\mathrm{a}}^{2} A_{\text {berg }} .
$$

We then assume that the force is concentrated along the strip of length $L$ and ice thickness $H$ that connects the berg to the rest of the ice shelf, resulting in a stress:

$$
\tau_{\mathrm{a}}^{\max }=\frac{C_{\mathrm{a}} \rho_{\mathrm{a}} U_{\mathrm{a}}^{2} A_{\text {berg }}}{H_{\mathrm{i}} L} .
$$

Equation (8) implies that larger icebergs may be more sensitive to wind stress than smaller bergs and that as the proto-berg continues to detach and $L$ decreases, the effect of wind stress will become increasingly important. For the Loose Tooth, the area of the rift system is approximately $900 \mathrm{~km}^{2}$ and the strip of material that connects T2 with L2 is still several kilometers long. Assuming $L$ to be $4 \mathrm{~km}$ and ice thickness $H_{\mathrm{i}}$ of $400 \mathrm{~m}$, this results in a maximum wind stress on the order of $10-20 \mathrm{kPa}$. This is still relatively small compared to the glaciological stress but is getting closer in magnitude than the other terms described above. For example, if $L$ were to decrease to $1 \mathrm{~km}, \tau_{\mathrm{a}}$ would be about $60 \mathrm{kPa}$, which is about one-third of the glaciological stress of the ice shelf. Likewise, a decrease in the ice thickness as the ice spreads outward or through enhanced melting could magnify the role of wind stress on the rift system. We thus expect winds to have an increasingly large effect as the Loose Tooth approaches complete detachment. In summary, our calculations suggest that wind stress may be more important for mature rift systems that are close to detachment, for proto-bergs with a larger surface area and for thin ice shelves with relatively small ice thickness. This may reconcile the observation that strong winds preceded the disintegration of the Larsen B ice shelf (Rott and others, 2002) and our observations that show that rift propagation is insensitive to wind speed. Because the Larsen B ice shelf, prior to collapse, was already heavily fractured and much thinner than the Amery, both $L$ and $H$ would have been much smaller, making the ice shelf much more sensitive to wind stress.

\section{Water stress $\left(\tau_{\mathrm{w}}\right)$}

The effect of water stress is similar to that of wind stress, with a quadratic dependency on water-current speed (Wadhams, 2000):

$$
\tau_{\mathrm{w}}=C_{\mathrm{w}} \rho_{\mathrm{w}} U_{\mathrm{w}}^{2}
$$

We denote the drag coefficient for water by $C_{w} ; \rho_{\mathrm{w}}$ is the density of water and $U_{w}$ is the current speed. Typical values for the drag coefficient for water are again of the order of $10^{-2}-10^{-1}$ (Wadhams, 2000). Ocean-current speeds are on the order of $1-10 \mathrm{~cm} \mathrm{~s}^{-1}$ and the density of water is approximately $1000 \mathrm{~kg} \mathrm{~m}^{-3}$. This implies that water stress is about one order of magnitude smaller than wind stress (typically $1-2 \mathrm{kPa}$ ). Subsurface topography of the rift may result in a form drag much larger than typical values of the skin drag over smoother portions of the ice shelf. With an increase in drag coefficient of one order of magnitude, water stresses could potentially have the same magnitude as wind stress. Again, if we assume that water drag is integrated over the proto-berg area and that force is concentrated along the band of material that connects the proto-berg to its parent ice shelf, this force can become significant. Qualitatively, we find the same result that we found for wind stress: (1) water stress will affect larger bergs more; (2) the effect of water stress will increase as the iceberg approaches detachment; and (3) the effect of water stress will increase as the ice thickness decreases. Unless there is a significant form drag caused by subsurface topography, we expect that wind stress will be more important in driving rift propagation than water stress.

\section{Tidal bending $\left(\tau_{\text {tide }}\right)$}

In addition to sub-ice-shelf currents, tides also induce flexure of the ice. Because the timescale of tidal variations is relatively short, we can approximate the deformation of ice as a quasi-static elastic response. To estimate the magnitude of bending stresses, we assume the ice can be treated quasi-statically using the elastic flexural wave equation (Turcotte and Schubert, 2002):

$$
D \frac{\mathrm{d}^{4} w}{\mathrm{~d} x^{4}}+\rho_{\mathrm{w}} g\left(w-\eta_{\text {tide }}\right)=0,
$$

where $w$ is the displacement of the beam and $\eta_{\text {tide }}$ is the tidal amplitude. $D$ is the flexural rigidity of ice given by

$$
D=\frac{E H_{\mathrm{i}}^{3}}{12\left(1-\nu^{2}\right)} \text {. }
$$

$E$ and $\nu$ are Young's modulus and Poisson's ratio for ice, respectively. For convenience we also introduce the length scale

$$
\alpha=\left(\frac{4 D}{\rho_{\mathrm{w}} g}\right)^{\frac{1}{4}},
$$

where $\alpha$ is often called the flexural wavelength. To calculate the bending stress from the tides, we assume a quasi-static sinusoidal tidal displacement with wavelength $\lambda=2 \pi / k$ :

$$
\eta_{\text {tide }}=A_{0} \mathrm{e}^{i k x} \text {. }
$$

We can find a solution to Equation (10) by assuming a solution of the form:

$$
w=w_{0} \mathrm{e}^{i k x}
$$

Substituting Equations (14) and (13) into Equation (10) we find the solution for the displacement:

$$
w=\frac{A_{0}}{\left(1+\alpha^{4} k^{4}\right)} \mathrm{e}^{i k x} .
$$

Equation (15) implies that wavelengths large compared to the flexural wavelength are locally isostatically compensated while those that are small compared to the flexural 

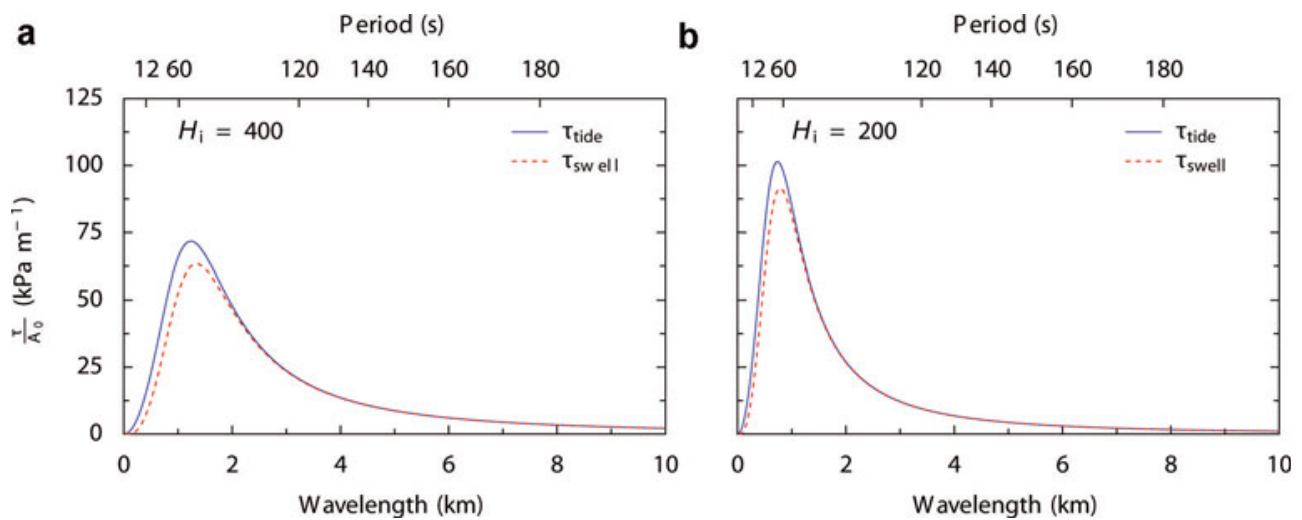

Fig. 8. Maximum bending stress as a function of fraction of flexural wavelength for tides (blue curve) and swell (dashed red curve) computed for ice $400 \mathrm{~m}$ thick (a) and $200 \mathrm{~m}$ thick (b). Values have been normalized per unit amplitude. The associated period of the flexural gravity waves is shown along the top axis of the panels.

wavelength induce no bending. The stress induced by flexure is related to the displacement by the equation (Turcotte and Schubert, 2002):

$$
\tau_{\text {tide }}=-\frac{E H_{\mathrm{i}}}{2\left(1-\nu^{2}\right)} \frac{\mathrm{d}^{2} w}{\mathrm{~d} x^{2}}
$$

The maximum bending stress occurs at either the top or bottom of the ice shelf (depending on the sign of the tide). Substituting Equation (15) into Equation (16) we find

$$
\tau_{\text {tide }}^{\max }=\frac{E H_{\mathrm{i}}}{2\left(1-\nu^{2}\right)} \frac{A_{0} k^{2}}{\left(1+\alpha^{4} k^{4}\right)},
$$

where we have omitted the $\exp (i k x)$ modulation of the magnitude. Figure 8 (blue line) shows the bending stress normalized to a $1 \mathrm{~m}$ tidal amplitude. Tides typically have wavelengths of $50-100 \mathrm{~km}$, approximately 80 times the flexural wavelength of ice. The mismatch between the flexural wavelength and the tidal wavelength yields low bending stress, of about $0.05-0.1 \mathrm{kPa}$. We see that for wavelengths comparable to the flexural wavelength (i.e. on the order of $1 \mathrm{~km}$ ), bending can induce a significant stress within the ice. While the wavelengths of tides are too long to be relevant, ocean swell, which we consider next, does have wavelengths within this range.

\section{Ocean swell ( $\left.\tau_{\text {swell }}\right)$}

Calculating the stress due to ocean swell is more complicated than for tides. The problem has received considerable attention in the sea-ice community to understand the impact of ocean swell on break-up of sea ice in the marginal zone (Goodman and others, 1980; Wadhams, 1986; Squire and others, 1995; Meylan and others, 1997). Following Wadhams (1986) we assume that an incoming plane wave of amplitude $A$, wavenumber $k$ and period $T=2 \pi / \omega$ is directly incident on the ice front. Including the frequency dependence, the flexural equation then becomes:

$$
D \frac{\mathrm{d}^{4}}{\mathrm{~d} x^{4}} w+\left(\rho_{\mathrm{w}} g-\rho_{\mathrm{i}} H_{\mathrm{i}} \omega^{2}\right) w=A \rho_{\mathrm{w}} g \mathrm{e}^{i k x} .
$$

See Goodman and others (1980) or Wadhams (1986) for a complete derivation of Equation (18). The only difference between this and the quasi-static approach used in modeling the effects of the tides is a frequency-dependent term $\rho_{\mathrm{i}} H_{\mathrm{i}} \omega^{2}$. In the limit as $\omega$ approaches zero (infinite period), we recover Equation (10). The amplitude $A$ of the wave is the amplitude of particle motion at the bottom of the ice shelf, not at the sea surface. Because this decreases exponentially with depth, the amplitude of the wave on the bottom of the ice shelf will be approximately related to surface amplitude by

$$
A=A_{0} \exp ^{\left(-k H_{\mathrm{i}} \rho_{\mathrm{i}} / \rho_{\mathrm{w}}\right)} .
$$

Detailed numerical solutions can be obtained for Equation (18) using a variety of numerical methods. Since we are interested in estimating the order of magnitude of bending stresses induced by swell, we adopt a simpler approach that avoids most of the complications. First, we introduce an additional length scale related to the frequency of the swell and the ice thickness:

$$
\beta=\left(\frac{4 D}{\rho_{\mathrm{i}} H_{\mathrm{i}} \omega^{2}}\right)^{4} .
$$

Next we substitute a solution of the form

$$
w=w_{0} \mathrm{e}^{i k x}
$$

into Equation (18), leading to the solution

$$
w=A \frac{\rho_{\mathrm{w}} g}{k^{4}+\left(\frac{1}{\alpha^{4}}-\frac{1}{\beta^{4}}\right)} \mathrm{e}^{i k x} .
$$

The more elaborate solutions of Goodman and others (1980) and Wadhams (1986) have the same amplitude as we have derived, but a different functional form due to the finite size of the ice floe they assumed and different boundary conditions they applied. Using Equation (16) we find that the amplitude of the maximum bending stress is:

$$
\tau_{\text {swell }}=\frac{E H_{\mathrm{i}}}{2\left(1-\nu^{2}\right)} \frac{A k^{2}}{\left(\alpha^{4} k^{4}+1-\frac{\alpha^{4}}{\beta^{4}}\right)},
$$

where we have omitted the $\mathrm{e}^{i k x}$ modulation of the bending stress. The final equation we need to close the system is the dispersion relation between the wavenumber, $k$, and frequency, $\omega$, of the incoming wave. The dispersion relation for flexural-gravity waves is given by (Wadhams, 2000):

$$
D k^{5}+\left(\rho_{\mathrm{w}} g-\rho_{\mathrm{i}} H_{\mathrm{i}} \omega^{2}\right) k-\rho_{\mathrm{w}} \omega^{2}=0 .
$$

Figure 8 shows the maximum bending stress for swell with a range of periods determined from the real root of Equation (24) normalized by a $1 \mathrm{~m}$ wave amplitude for (1) a $400 \mathrm{~m}$ thick ice shelf (Fig. 8a) and (2) a $200 \mathrm{~m}$ thick ice shelf (Fig. 8b). Most of the energy of ocean swell is concentrated 
Table 1. Summary of the results of the order-of-magnitude calculations of each term in the force balance represented in Equation (1)

\begin{tabular}{ccc}
\hline Stress & Symbol & Magnitude \\
& $\mathrm{kPa}$
\end{tabular}

$\mathrm{kPa}$

\begin{tabular}{llc}
\hline Glaciological stress & $\tau_{\mathrm{i}}$ & $\mathbf{2 0 0}$ \\
Wind stress & $\tau_{\mathrm{a}}$ & 15 \\
Bending from swell & $\tau_{\text {swell }}$ & 10 \\
Water stress & $\tau_{\mathrm{w}}$ & 1.5 \\
Sea surface tilt & $\tau_{\mathrm{t}}$ & 1 \\
Bending from tides & $\tau_{\text {tide }}$ & 0.1 \\
Coriolis force & $\tau_{\mathrm{c}}$ & 0.001 \\
\hline
\end{tabular}

in wavelengths less than $700 \mathrm{~m}$, with a long tail of decreasing energy at longer periods (Pond and Pickard, 1983). These wavelengths are still smaller than the flexural wavelength of ice, but the wavelengths are closer in magnitude to the flexural wavelength than those of the ocean tides and have the potential to cause a significantly larger stress within the ice. Assuming a normal background swell with an amplitude of 1-2 $\mathrm{m}$ (wave height of 2-4 m) and periods in the range $8-12 \mathrm{~s}$, this corresponds to a stress of approximately $10 \mathrm{kPa}$ for an ice shelf $400 \mathrm{~m}$ thick, and $35 \mathrm{kPa}$ for an ice shelf $200 \mathrm{~m}$ thick. This stress remains small compared to the glaciological stress, suggesting that normal ocean swell incident on the ice shelf will have a small effect on rift propagation. Although pulses of large-amplitude ocean swell may be important in triggering propagation in rifts very close to the ice front, for most ice shelves the influence of swell is small compared to the glaciological stress within the ice. It is possible, however, that ice shelves that are thin and have many pre-existing fractures, such as iceberg B15 prior to break-up (MacAyeal and others, 2007), the Larsen B ice shelf prior to disintegration (Scambos and others, 2003) and the remaining Arctic ice shelves, are more susceptible to break-up triggered by ocean swell.

\subsection{Primary driver of rift propagation}

Table 1 summarizes our estimates of the stress transmitted to the ice shelf by each term in the force balance. Of all the variables we considered, the internal glaciological stress is the dominant term in the force-balance equation. Rather than introduce more complicated models in which stress accumulates or additional interactions with the environment, the simplest hypothesis is that rift propagation is primarily driven by the glaciological stress. Short-term environmental variables may be important in some situations (e.g. for thin ice shelves and in the period immediately before iceberg detachment), but we suggest that these effects are higher-order terms superimposed on the dominant glaciological stress.

An outstanding question after concluding that glaciological stress is dominating the rift propagation process is: since glaciological stress is relatively constant, why is rift propagation episodic? One possible explanation is that the episodic rift propagation events are related to the crystal structure of ice. There is evidence for this in ice fracture experiments (Rist and others, 2002). This behavior occurs over a small spatial scale (typically centimeters to tens of centimeters) and is usually ascribed to the crystal structure of ice or brine pockets within the ice. Over the larger length scales of rift propagation (hundreds to thousands of meters), these microscopic effects will become less and less important (Bassis and others, 2007). Moreover, episodic behaviour appears to be a feature of crack propagation in a variety of materials over a range of spatio-temporal scales (e.g. earthquakes). Episodic propagation is clearly not a property unique to ice. Instead, in a companion paper, we have suggested that rift propagation occurs over a sequence of steps involving the initiation of smaller micro- and mesoscale cracks ahead of the rift tip (Bassis and others, 2007). As the density of these cracks increases, they eventually coalesce into a single crack extending the length of the rift. This process has been observed in fracture-mechanics experiments of rocks (Reches and Lockner, 1994). The implication is that ice-shelf rift propagation may be similar in nature to brittle failure of rocks and that episodic rupture events may be a general feature of fracture as opposed to a specific property of ice. A crucial issue that remains is, to what degree does surface melt accelerate this process? Addressing this issue requires observations that span at least a full annual cycle, and in regions that experience varying amounts of surface melt.

\section{CONCLUSIONS}

We have explored the link between rift propagation events and a range of environmental variables. We find no evidence to suggest that rift propagation is driven by shortterm variations in environmental variables. Instead, our observations show that rift propagation is insensitive to winds and tides (over the timescale of our measurements) and that even a significant impulse input, such as the tsunami generated by the 26 December 2004 Sumatra earthquake, did not trigger rift propagation. The insensitivity of rift propagation rates to sea-ice fraction shows that pulses of ocean swell are not likely to be driving rift propagation. The lack of direct influence of environmental stresses is supported by order-of-magnitude calculations which show that while most environmental variables exert a stress on the ice shelf, they are small compared to the glaciological stress. However, we also find that frictional stresses from the wind and ocean may become increasingly important as the rift system becomes more mature and iceberg detachment becomes imminent. We find that ocean swell may play a larger role in driving ice-shelf rift propagation in certain special cases: for thinner ice shelves; for rifts very close to the ice front; or for rifts in late stages of development. Nonetheless, the largest term in the force balance for most ice shelves is the glaciological stress and we suggest that this is the primary driving stress involved in iceberg calving. Extreme environmental events with amplitudes beyond the parameter regime that we have been able to measure may trigger propagation events, but we argue that these extrema are not necessary conditions for rift propagation to occur.

The lack of influence of short-term environmental forces is encouraging for numerical modeling of the iceberg calving process because it implies that such models do not need to take into account potentially complicated short-term interactions with either the atmosphere or ocean over daily or shorter timescales. This has important implications for how tightly numerical ice-sheet/-shelf models need to be coupled to global- and regional-scale ocean and atmosphere models. To fully assess the role of environmental variables, especially surface melt, it is important to measure rift 
propagation for a larger set of rifts in a wider range of environmental conditions over longer time periods.

\section{ACKNOWLEDGEMENTS}

This work was supported by the US National Science Foundation Office for Polar Programs through grant NSF0337838, an Australian Research Council Discovery Grant and Australian Antarctic Science grants. We thank Raytheon Polar Services and the Australian Antarctic Division for logistical support during the fieldwork, and the University Navstar Consortium (UNAVCO) and the Program for the Array Seismic Studies of the Continental Lithosphere (PASSCAL) for loan of the scientific equipment. We thank I. Allison and the AAD Glaciology Program for providing AWS data, along with the Australian National Tide Center for providing tide gauge data for Davis station. We also thank J. Behrens, D. Darnell, M. Okal, B. Legrésy and V. Janssen for invaluable assistance in the field, D. MacAyeal and $M$. Cathles for helpful discussions on the interaction of ocean swell with ice shelves and K. Brunt for assistance in making maps.

\section{REFERENCES}

Alley, R.B., T.K. Dupont, B.R. Parizek and S. Anandakrishnan. 2005. Access of surface meltwater to beds of sub-freezing glaciers: preliminary insights. Ann. Glaciol., 40, 8-14.

Bassis, J.N., R. Coleman, H.A. Fricker and J.B. Minster. 2005. Episodic propagation of a rift on the Amery Ice Shelf, East Antarctica. Geophys. Res. Lett., 32(6), L06502. (10.1029/ 2004GL022048.)

Bassis, J.N. and 7 others. 2007. Seismicity and deformation associated with ice-shelf rift propagation. J. Glaciol., 53(183), 523-536.

Fricker, H.A., N.W. Young, I. Allison and R. Coleman. 2002. Iceberg calving from the Amery Ice Shelf, East Antarctica. Ann. Glaciol., 34, 241-246.

Fricker, H.A., N.W. Young, R. Coleman, J.N. Bassis and J.B. Minster. 2005. Multi-year monitoring of rift propagation on the Amery Ice Shelf, East Antarctica. Geophys. Res. Lett., 32(2), L02502. (10.1029/2004GL021036.)

Gill, A.E. 1982. Atmosphere-ocean dynamics. San Diego, CA, Academic Press.

Goodman, D.J., P. Wadhams and V.A. Squire. 1980. The flexural response of a tabular ice island to ocean swell. Ann. Glaciol., 1, 23-27.

Holdsworth, G. and J.E. Glynn. 1978. Iceberg calving from floating glaciers by a vibrating mechanism. Nature, 274(5670), 464-466.

Jacobs, S.S., H.H. Hellmer, C.S.M. Doake, A. Jenkins and R.M. Frolich. 1992. Melting of ice shelves and the mass balance of Antarctica. J. Glaciol., 38(130), 375-387.

Joughin, I. and D.R. MacAyeal. 2005. Calving of large tabular icebergs from ice shelf rift systems. Geophys. Res. Lett., 32(2), L02501. (10.1029/2004GL020978.)
Joughin, I. and L. Padman. 2003. Melting and freezing beneath Filchner-Ronne Ice Shelf, Antarctica. Geophys. Res. Lett., 30(9), 1477-1480.

Larour, E., E. Rignot and D. Aubry. 2004. Modelling of rift propagation on Ronne Ice Shelf, Antarctica, and sensitivity to climate change. Geophys. Res. Lett., 31(16), L16404. (10.1029/ 2004GL020077.)

Lemke, P. and 10 others. 2007. Observations: changes in snow, ice and frozen ground. In Solomon, S. and 7 others, eds. Climate change 2007: the physical science basis. Contribution of Working Group I to the Fourth Assessment Report of the Intergovernmental Panel on Climate Change. Cambridge, etc., Cambridge University Press.

MacAyeal, D.R. and 13 others. 2007. Transoceanic wave propagation links iceberg calving margins of Antarctica with storms in tropics and Northern Hemisphere. Geophys. Res. Lett., 33(17), L17502. (10.1029/2006GL027235.)

Meylan, M., V.A. Squire and C. Fox. 1997. Towards realism in modelling ocean wave behavior in marginal ice zones. J. Geophys. Res., 102(C10), 22,981-22,991.

Padman, L., H.A. Fricker, R. Coleman, S. Howard and L. Erofeeva. 2002. A new tide model for the Antarctic ice shelves and seas. Ann. Glaciol., 34, 247-254.

Pond, S. and G.L. Pickard. 1983. Introductory dynamical oceanography. Second edition. Oxford, etc., Butterworth-Heinemann.

Reches, Z. and D.A. Lockner. 1994. Nucleation and growth of faults in brittle rocks. J. Geophys. Res., 99(B9), 18,159-18,174.

Rignot, E., G. Casassa, P. Gogineni, W. Krabill, A. Rivera and R. Thomas. 2004. Accelerated ice discharge from the Antarctic Peninsula following the collapse of Larsen B ice shelf. Geophys. Res. Lett., 31(18), L18401. (10.1029/2004GL020697.)

Rist, M.A., P.R. Sammonds, H. Oerter and C.S.M. Doake. 2002. Fracture of Antarctic shelf ice. J. Geophys. Res., 107(B1). (10.1029/2000JB000058.)

Rott, H., W. Rack, P. Skvarca and H. De Angelis. 2002. Northern Larsen Ice Shelf, Antarctica: further retreat after collapse. Ann. Glaciol., 34, 277-282.

Scambos, T., C. Hulbe and M. Fahnestock. 2003. Climate-induced ice shelf disintegration in the Antarctic Peninsula. In Domack, E.W., A. Burnett, A. Leventer, P. Conley, M. Kirby and R. Bindschadler, eds. Antarctic Peninsula climate variability: a historical and paleoenvironmental perspective. Washington, DC, American Geophysical Union, 79-92. (Antarctic Research Series 79.)

Scambos, T.A., J.A. Bohlander, C.A. Shuman and P. Skvarca. 2004. Glacier acceleration and thinning after ice shelf collapse in the Larsen B embayment, Antarctica. Geophys. Res. Lett., 31(18), L18402. (10.1029/2004GL020670.)

Squire, V.A., J.P. Dugan, P. Wadhams, P.J. Rottier and A.K. Liu. 1995. Of ocean waves and sea ice. Annu. Rev. Fluid Mech., 27, 115-168.

Turcotte, D.L. and G. Schubert. 2002. Geodynamics. Second edition. Cambridge, etc., Cambridge University Press.

Wadhams, P. 1986. The seasonal ice zone. In Untersteiner, N., ed. Geophysics of sea ice. London, etc., Plenum Press, 825-991.

Wadhams, P. 2000. Ice in the ocean. Amsterdam, etc., Gordon and Breach Science Publishers.

Weertman, J. 1957. Deformation of floating ice shelves. J. Glaciol., 3(21), 38-42. 